\title{
LA ESCUELA DE FRANKFURT Y HABERMAS: EL DEBATE SOBRE LA HERENCIA DE LA TEORÍA CRÍTICA* Helmut Dubiel**
}

P arece insostenible referirse hoy a la Escuela de Frankfurt como una cuestión histórica. La edición de sus trabajos en impresionantes "Obras completas", una serie de archivos bien organizados y una inabarcable literatura secundaria constatan que el origen y el contexto de su pensamiento pueden documentarse sin remates.

La Teoría Crítica parece convertirse en una virulencia político-espiritual aceptada en Alemania. Mostrarse abiertamente en su tradición no es, como en otro tiempo, signo de disidencia radical. El establisment ha aprendido a decir junto con la Teoría Crítica que se puede vivir junto a sus representantes contemporáneos.

Esto, sin embargo, no significa que el material polémico y conflictivo que la Teoría Crítica encierra en sus categorías esotéricas se haya hecho

* El presente trabajo fue presentado como ponencia al Congreso "Sobre la actualidad de la Escuela de Frankfurt", organizado por la Erasmus University de Rotterdamn a fines de 1988 y publicado en Zwischen-betrachtungen: im Prozess der Aufklärung por la editorial Suhrkamp, 1989. Traducción de Blanca Solares.

** Director del Institut für Sozialforschung de la Universidad de Frankfurt. Co-autor del libro Die demokratische Frage, 1989. 


\section{Helmut Dubiel}

menos problemático. La discusión sobre su continuidad, con proyectos teóricos tradicionalmente opuestos, sólo se ha traspasado a las relaciones internas de sus adeptos. Es decir que, los descendientes de la Teoría Crítica se enfrentan hoy internamente unos con otros.

Esta disputa, por tradición propia de Alemania, quizá no tenga la visibilidad pública del Debate sobre la historia alemana (Historikerstreit), pero tampoco se limita como en el caso del Debate sobre el Positivismo (Positivismustreit) a las fronteras de la República ilustrada. En esta controversia, para expresarlo de alguna forma, los conflictos fundamentales y convencionales de la Linksintelligent (Inteligencia de la izquierda) serán nuevamente rebasados por las condiciones de desarrollo alcanzado en las sociedades de capitalismo tardío. La interpretación propia de la tradición crítica convencional sobre la sociedad contemporánea es sólo una posibilidad; si bien la más importante, sobre la que el conflicto fundamental de la herencia de la Teoría Crítica logra expresarse en el ámbito intelectual.

Apenas si es necesario plantear algunas preguntas para, alrededor de sus respuestas contrastantes, alinear rápidamente los puntos de las tendencias en debate. Se trataría de incógnitas, como las siguientes: ¿Es posible controlar de forma social y jurídica la dinámica destructiva del capitalismo? ¿Es posible participar en la democracia burguesa, pese al sentido del control estratégico? ¿Son las formas de conciencia empírica de las agrupaciones sociales, de los trabajadores o de la juventud, por ejemplo, sólo la expresión de formas establecidas de dominio o contienen también un punto de partida emancipatorio? ¿Es posible la existencia diferenciada de la subjetividad en las condiciones de la sociedad actual?

Siempre que el debate político-teórico se concentra en puntos problemáticos tales, el estado político-espiritual de la Teoría Crítica se polariza de acuerdo a una lógica peculiar. Es el carácter singular de esta lógica el que me interesa trabajar analíticamente en las siguientes líneas.

Si agrupamos las respuestas a estas cuestiones centrales en la teoría del capitalismo tardío y las relacionamos con el proceso de desarrollo de la Teoría Crítica, de sus orígenes a su situación actual, es posible observar lo siguiente: aquellos que no confían en una dinámica controlable del capitalismo, que conciben a la democracia, en último término, como una 


\section{LA ESCUELA DE FRANKFURT Y HABERMAS}

confabulación ideológica y a las formas de conciencia emancipatorias como improbables en la sociedad actual, se inclinan por la variante radical de la Teoría Crítica de la Dialéctica del iluminismo. En sentido opuesto, aquellos que contradicen tales respuestas apoyan más bien la variante de la Teoría Crítica expuesta por Jürgen Habermas, en la Teoría de la acción comunicativa. De forma esquemática, podríamos representar esta escisión en la Teoría Crítica del capitalismo tardío como oposición entre pesimismo y optimismo, entre una imagen oscura y una luminosa, entre el "Gran Hotel del Abismo" (Gran Hotel Abgrund) y una euforia comunicativa apolítica.

Este tipo de simplificaciones, sin embargo, no es posible. La diversidad de motivos y la complejidad de ambas variantes de la Teoría Crítica impiden una escisión tan claramente diferenciada entre lo que podríamos llamar, una teoría de la dominación pura y una teoría abstracta de la emancipación. Sabemos que la Dialéctica del iluminismo fue escrita, si bien con escepticismo, con la esperanza en un horizonte virtual de liberación, mientras que en las categorías habermasianas centrales de "integración sistémica", se encuentran contenidas también muchas de las implicaciones teóricas en torno a la categoría de dominio de la Teoría Crítica clásica.

Por lo demás, tampoco resulta absurdo el que ambas vertientes de la Teoría Crítica se relacionen de forma no dialéctica. Pues ambas reflexionan, incluso hasta en las estructuras básicas de sus categorías, desde la especificidad de su contexto histórico de surgimiento. La primera es una teoría del capitalismo tardío totalitario; la segunda, una teoría del Estado de Bienestar Social de la democracia de masas posterior al fascismo.

Naturalmente, no intento aquí un tratamiento filológico del tema, pero sí tratar de poner en claro el carácter de la opinión difundida, en el sentido de que ambas variantes de la Teoría Crítica son irreductibles.

Para determinar las características de este presupuesto trataré de esbozar una suerte de perfil polar entre la teoría de Adorno y Horkheimer por un lado, y la de Habermas, por el otro. Me propongo realizar este intento a través de tres momentos.

Planteo primero un cuestionamiento de los supuestos metateóricos de 
Helmut Dubiel

ambas vertientes de la Teoría Crítica. Segundo, trato la relación de ambas teorías con el proceso de conformación de la voluntad política. Tercero, comparo entre sí los juicios contenidos en ellas sobre el desenvolvimiento actual del proceso histórico.

1. En Dialéctica del iluminismo, Horkheimer y Adorno desarrollan una crítica global de la tradición occidental de la razón desde sus orígenes, desde sus comienzos en la historia antigua, hasta la contemporaneidad de una racionalidad formal de contenidos totalitarios; aluden e identifican con ello un fenómeno que lo abarca y lo domina todo. Para Adorno y Horkheimer las ciencias especializadas, y la filosofía académica incluida, no son sino formas inconscientes de apropiación instrumental del hombre sobre la naturaleza como condición propia y externa.

Esta convicción de la Teoría Crítica, particularmente en Adorno, es conscientemente paradójica porque surge de la praxis, en el aliento de un filosofar cuyas posibilidades él mismo socava. Si bien en los años treinta, los años de fundación de la Teoría Crítica, sus autores sostienen que aun en el capitalismo totalitario, en las estructuras e instituciones

44 decadentes de la cultura burguesa, existen estructuras básicas a las que la Teoría Crítica puede vincularse, en Dialéctica del iluminismo -una década más tarde- Adorno y Horkheimer se apartan de aquella expectativa y desplazan su concepción teórica hasta el punto más extremo de la crítica radical de la razón. Pensar en establecer vínculos con la razón personalizada cultural o institucionalmente ya no será posible desde de esa perspectiva teórica. Es frente a esta "pérdida de objetividad de la crítica de la razón", extremadamente radicalizada que Habermas reacciona.

Habermas reconoce y admira en principio, el acto de equilibrio fundamental de la crítica radical de la razón de Adorno y Horkheimer, pero disiente respecto al hecho de que los "espíritus endebles" hubieran podido escapar de las premisas de resultados irracionalistas indirectos. Para Habermas, la forma de exposición paradójica de la Teoría Crítica en Dialéctica del iluminismo y, particularmente, en Dialéctica negativa aparece como una auto-contradicción performativa. Alude con esto a que la fatalidad que marca Dialéctica del iluminismo como imposibilidad de una auto-ilustración teórica real de los hombres, tendría que haber 


\section{LA ESCUELA DE FRANKFURT Y HABERMAS}

hecho imposible también esta obra. Porque, ¿cómo pueden garantizar sus autores que su propio trabajo teórico no esté afectado por el remolino de la razón instrumental?

Preocupado por el eje organizador de su propia filosofía, Habermas se remite gustoso al propósito de dar a la teoría crítica de la sociedad una base conceptual firme que, según él, no puede partir de un trauma histórico-epocal. Esta fundamentación toma forma en el concepto de racionalidad (Vernunft) comunicativa; es decir, en un concepto que funda las posibilidades de la acción racional sobre estructuras antropológicas básicas y formas institucionales del entendimiento humano.

2. La Dialéctica del iluminismo está dominada por un escepticismo esencial respecto a la capacidad actual de los hombres para determinar sus relaciones sociales de vida de acuerdo a su voluntad y conciencia propias. En la Teoría Crítica clásica, en este sentido, no existe espacio teórico alguno para la reflexión sobre instituciones de conformación de la voluntad política. Adorno y Horkheimer sostienen la perspectiva analítica de que la cultura de masas del capitalismo tardío y el aparato coercitivo del fascismo determinan tan extremadamente el ámbito de posibilidad de constitución de la voluntad política que los hombres ya no pueden ser concebidos, ni siquiera utópicamente, como sujetos autónomos.

Habermas, por su parte, se caracteriza a sí mismo, no sin ironía, como pupilo de una etapa de "re-education" en Alemania. El acicate específico de su filosofía es la sustancia moral oculta en los fundamentos constituivos de la sociedad occidental. Su idea teórico-política básica es que, a partir de la atrofia de los medios tradicionales de unificación de la voluntad, los nexos de acción política sólo pueden ser coordinados a partir de actos de entendimiento (Verständigung) colectivos. De ahí el principio, de que sólo ciertas organizaciones políticas puedan hoy pretender el respeto de sus ciudadanos: aquellas capaces de garantizar el proceso de formación y de coordinación comunicativa.

Este elemento de trasfondo teórico-político esclarece la importancia sobresaliente que toman en su teoría la opinión pública política, el derecho jurídico en las decisiones estatales y los fenómenos de la cultura democrática. 
Helmut Dubiel

3. El tercer punto de diferencia ocupa la mayor parte del conflicto entre partidarios de la Teoría Crítica Clásica y la actual. Desde un punto de vista superficial éste podría caracterizarse como oposición entre pesimismo histórico-filosófico y optimismo.

La Dialéctica del iluminismo es una filosofía negativa de la historia que establece afirmaciones sobre el desarrollo histórico de la especie humana en su globalidad. El proceso histórico aparece para Adorno y Horkheimer como ascenso del poder de la razón instrumental, permanente e incontrolable. La historia es como una curva de decadencia y ruina cuya sima histórica no es sino el fascismo.

Habermas, por el contrario, está convencido -en contradicción incluso con algunos de sus primeros escritos- de que no es posible hacer exposiciones sobre el desarrollo de la especie humana de forma global. Frente a la perspectiva unilateral y negativa de Dialéctica del iluminismo establece que, para él, la historia es en cada momento una unidad de tendencias contradictorias que de ninguna manera se deja apresar en el ámbito unívoco de "progreso" o "decadencia". Este distanciamiento de Habermas del análisis filosófico-histórico negativo de Dialéctica del iluminismo funda una forma de teorización propia.

Habermas muestra una fuerte tendencia hacia los modelos de interpretación de la lógica de desarrollo, particularmente en sus escritos de los años setenta. Su concepto de "Entwiklungslogik" (lógica de desarrollo) alude a una de las perspectivas tomadas de la psicología de Piaget y de Kohlberg y obedece al proceso de formación individual y colectivo de una lógica de desarrollo que va auto-estableciéndose de forma consecuente. Tal proceso de formación puede ser descrito, por lo tanto, como secuencia de grados de desarrollo irreversibles. Estos niveles de desarrollo de formas de conciencia práctico-moral tienen un sentido directamente opuesto a la perspectiva teórica del ocaso de la historia humana presentado en Dialéctica del iluminismo. Ya que apunta, tanto en los individuos como en los grupos, no hacia un aumento de dominio sino de autonomía. En el nivel más alto de desarrollo de este esquema se establece la capacidad de decisión autónoma de los actores, es decir, la energía moral de éstos para la crítica y revisión de sus convenciones sociales a la luz de sus propios principios. 


\section{LA ESCUELA DE FRANKFURT Y HABERMAS}

A decir verdad, Habermas no está convencido de que un proceso de desarrollo lógico tal sea realmente válido en los procesos de formación colectiva. No obstante, plantea esto como modelo heurístico, por ejemplo, para el análisis de la orientación de los valores culturales, de la dinámica del Estado de derecho y de la configuración de formas de conciencia democráticas. Se mantiene a sí mismo firme en la antinomia obstinada, es decir en el convencimiento, de que en el desarrollo del Estado de bienestar de la democracia de masas existe algo así como la institucionalización de "trinquetes" ("Sperrklinkenefekten") o seguros de recaída que garantizan, de alguna manera, que una sociedad que se ha desarrollado de modo democrático no retroceda a niveles inferiores. Frente al pesimismo radical de trasfondo de Dialéctica del iluminismo, este interés teórico por la sustancia de las formas de conciencia y de las instituciones jurídicas y democráticas aparece ahora como la expresión de un enfoque esencialmente histórico-optimista.

En realidad ninguna de estas vertientes de la teoría crítica opera de forma pura o complementaria, una como teoría del dominio y la otra como teoría de la emancipación. Habermas, especialmente, se esfuerza en tratar de integrar ambos puntos de vista. Con todo, su construcción teórica indica desde un principio la primacía de la coordinación del mundo de la vida en las relaciones de la acción. De acuerdo con esta premisa no es imaginable que, de pronto, tales capacidades de coordinación se deleguen de forma exclusiva en mecanismos sistemáticos. Pero, es a partir de tal situación que los autores de Dialéctica del iluminismo proyectan su teorización crítica.

Si se observa a la Teoría Crítica desde su concepción originaria es claro que Horkheimer adopta el concepto de crítica de la Crítica de la economía política de Marx. La reconstrucción de Horkheimer del método de Marx contiene dos momentos que en el curso de su descripción teórica se separan: la fenomenología objetivista de la relación de dominio y una elaboración teórica de la posibilidad de superar esa relación a través de una acción práctica. Aunque estos momentos corresponden a una unidad, la separación de ambos se mantiene en las tendencias actuales de su público potencial.

Quisiera distanciarme ahora de las vertientes expuestas para hablar 


\section{Helmut Dubiel}

de los estereotipos profundamente asentados a partir de los cuales se perciben proyectos diferenciados de Teoría Crítica, uno enfrentándose al otro.

Los partidarios de la Teoría Crítica clásica describen a la sociedad desde la perspectiva de una dominación coercitiva que, vista en detalle, ofrece una imagen incierta acerca de si se refiere a una imposición que ha sido ya consagrada o al destino de una tendencia irreversible. Los presupuestos de un dominio que se ha establecido ya por entero, pueden relacionarse con las estructuras de la subsunción real bajo el capital, la dialéctica de la coerción sobre la naturaleza, los imperativos desencadenados por el desarrollo científico-técnico y los supuestos de la sociedad patriarcal. El criterio a partir del cual estas estructuras de dominio o de coerción son descritas corresponden en último término al de un observador situado como al margen del proceso. Esta perspectiva es necesaria porque naturalmente tiene que explicarse cómo, pese a todo, es posible una Teoría Crítica como teoría del dominio totalitario. Y al parecer, ésta sólo es posible en la medida en que reclame para sí un resguardo-si bien también amenazado- fuera de las relaciones de dominio que describe. El status de la víctima del dominio totalitario es incompatible, por lo tanto, con el del sujeto de la Teoría Crítica.

El planteamiento de una relación de dominio total y absoluto resulta sin embargo absurdo porque, tanto la teoría como el mundo de la vida pre-teórico son actos vinculados de forma necesaria con la idea de que el campo de acción en el cual me muevo en situaciones de acción problemáticas, no está cerrado por completo. La opción del acto interno de elegir una cosa u otra, la posibilidad de cerciorarme de forma reflexiva de ello, la experiencia propia como individuo con capacidad de acción, tiene un fundamento antropológico. Mientras que, una situación en la que estuviera obligado a experimentarme permanentemente como víctima del dominio totalitario - privado de toda posibilidad de acción- me suprimiría propiamente como sujeto. En la literatura, la figura de los "musulmanes" que evoca a los reclusos de los campos de concentración y se relaciona con el fatalismo islámico, caracteriza como reclusos sólo a aquellos que, al pie de la letra, se convierten en objetos del dominio totalitario cuando internalizan las condiciones de la concentración. Bru- 


\section{LA ESCUELA DE FRANKFURT Y HABERMAS}

no Bettelheim y Primo Levi describen de forma sobrecogedora como esta auto-negación impuesta daña al sujeto incluso físicamente y cómo los "musulmanes" que optan con su sumisión al dominio de sus circunstancias lo hacen, al mismo tiempo, por su muerte.

La idea a priori de un dominio establecido ya de forma absoluta conduce necesariamente a deformaciones específicas en la descripción de los fenómenos real-empíricos. Puede observarse así a los fenómenos culturales y a la economía moral de grupos sociales colectivos como objetos destruidos o como materiales para la carburación de un proceso histórico al margen de personas con voluntad y conciencia propias. Esta perspectiva de la subsunción a través de una pretendida dirección analítica hace que la lógica misma del término "subsunción" apenas pueda contemplar como material de trabajo a los actos de resistencia, desequilibrio, ruptura y protesta contra la imposición de estructuras sistemáticas. Una perspectiva tal de la teoría de la subsunción exige así de los teóricos críticos un precio moral, del que Adorno en cierto sentido era bastante consciente en su debate con Erich Fromm.

La lógica interna de la perspectiva del observador, cuando reflexiona, lo obliga a contemplar a la víctima del proceso de subsunción -al objeto del dominio- con una frialdad neutral moralista cercana a la del dominador. En determinados sectores la fascinación abierta o silenciada de la Teoría Crítica encuentra aquí su origen. Lo que no puede ponerse en duda es que esta teoría del dominio totalitario, planteada desde la perspectiva del observador, está escrita sobre la base de su identificación ética y moral con las víctimas. Y que esta conciencia no se produce desde sí misma sino que se introduce, como reconocimiento moral, desde fuera. A manera de ejemplo, es esto lo que permitiría al teórico marxista del mercado mundial que estudia los movimientos migratorios de capital, desde la perspectiva del observador puro, aplicar sus conocimientos también como especulador de la bolsa. Que no lo haga, cuando no lo hace, de ninguna manera es un problema trivial. Tiene que ver con el hecho de que la Teoría Crítica en sí no puede existir al margen del impulso moral de su horizonte de desenvolvimiento.

La otra interpretación de la Teoría Crítica se relaciona internamente con la perspectiva del partícipe en la luchas sociales real-empíricas. 
Helmut Dubiel

Tiene que ver en cierta forma con el cercioramiento reflexivo de los potenciales políticos contestatarios, a los que puede estimular o fortalecer, pero nunca anexarse a ellos incondicionalmente. Concibe la historia sobre la base de intereses y posibilidades de resistencia opuestos al establecimiento del dominio totalitario y fija su atención en las barreras morales e institucionales que los obstaculizan e impiden. Frente a los planteamientos marginal-elitistas de la "vieja" Teoría Crítica -que se define adecuadamente en una formulación concisa de Martin Jay como "exilio en la permanencia" - toma lugar esta otra interpretación de la Teoría Crítica vinculada en sí con la sociedad a la que describe. En este sentido, no pretende, ni siquiera en su forma (Gestalt) conceptualmente elaborada, introducir definiciones necesarias de la realidad para contraponerlas luego a la auto-comprensión "aparentemente" innata de los actores sociales. Ni decreta ninguna certeza histórico-filosófica o proceso objetivista de juicios posibles y definitivos sobre la realidad social. La instancia que orienta su forma teórica es en último término la del razonamiento público de los actores ilustrados. Su análisis cognitivo de las condiciones de acción y la reflexión sobre los impulsos de ésta tampoco se encuentran predeterminados por medio de una racionalidad sobre la cual sólo dispone la teoría. Se trabaja, a decir verdad, con la diferencia entre opiniones bien o mal fundamentadas, pero no entre juicio "verdadero" o "falso". El ámbito no-trascendental sobre el que esta vertiente realiza sus intervenciones no es sino el de la discusión pública.

Así pues he intentado hacer claras estas dos estilizaciones en el debate. Me he referido, por un lado, a la perspectiva de un observador como al margen del proceso, que no puede comprobar sus impulsos motivacionales desde el ámbito de sus propias premisas teóricas; y por el otro, a la figura de un partícipe como en tinieblas en la imagen de un proceso de formación de la voluntad que teóricamente no es juzgable a priori. Es decir, de un proceso público y no determinado que, en principio, contiene y coloca cualquier opinión en igualdad de jerarquía respecto al centro del ámbito político.

$\mathrm{Al}$ acentuar tales unilateralidades se advierte sin embargo que la teoría crítica de la sociedad sólo puede constituirse si ambas perspectivas teóricas de trabajo se complementan. La teoría no puede dejar de ser 


\section{LA ESCUELA DE FRANKFURT Y HABERMAS}

pensamiento ilustrado de la situación de los actores colectivos, pero del mismo modo, tampoco puede agotarse en la simple percepción acrítica que acompaña a las formas de resitencia y rebelión contemporáneas.

Cuando en 1937 Horkheimer introdujo el concepto de "Teoría Crítica" sostenía la tesis incierta de que el intelectual crítico estaba obligado a mantener la claridad de su perspectiva teórica a través del distanciamiento social de sus destinatarios políticos. Pero también le era claro que la solidaridad moral de los intelectuales con los movimientos sociales reales y su distancia de la inmediatez de formas de conciencia empírica son cuestionables cuando se desvanece el horizonte comunicativo entre el sujeto de la teoría y su destinatario.

El interés teórico de la Teoría Crítica clásica se centra en el análisis del dominio y en los mecanismos a partir de los cuales se reproducen las relaciones de subyugación. Cuestión de la que deriva una selectividad empírico-peculiar de temas. Se preocupa, por ejemplo, por los mecanismos de los instintos que inducen al individuo a mantener una estructura de acción opuesta a sus intereses racionales propios y analiza las ideologías que encubren las peculiaridades del dominio en uso, detrás del velo del "interés general" que facilita un equilibrio adecuado del dominio de la conciencia colectiva.

Esta comprensión completa el intento de un examen centrado de forma prioritaria en los potenciales de emancipación de individuos y de grupos, de los mecanismos del "mundo de la vida" que se oponen al funcionamiento del dominio, de sus enfermedades morales y de los potenciales de rebelión como obstáculos para una afirmación individual libre. Este desarrollo de la Teoría Crítica interpreta las experiencias de los individuos desde un plano distinto a aquel en el que éstas se articulan. Complementa de forma sorprendente a la universalización de la ideología del escepticismo planteada en Dialéctica del iluminismo inclinándose por la sospecha de la racionalidad, pero haciéndola extensiva también al ámbito pre-hablado (vorsprachlichen Bezirke) de las personas. Una tendencia de la fantasía social-psicológica de esta variante de la Teoría Crítica pone su atención en las reacciones externas del cuerpo, en las molestias psico-somáticas o en el ausentismo de los trabajadores, con 
Helmut Dubiel

objeto de descifrar en tales potenciales, en los actos silenciosos, la negación de la funcionalidad cotidiana.

La "vieja" versión radical e irrefutable de la Teoría Crítica, por su parte, aclara sólo el comportamiento conformista de los individuos. De acuerdo a su concepción, las fuerzas de los instintos propias del proceso histórico no son conducidas por la colectividad sino por una regresión institucionalizada o por imperativos funcionales respecto a los cuales esos colectivos reaccionan sólo mecánicamente. Los sujetos aparecen apenas como órganos de una voluntad, ajena a sí misma o como lo contrario de su concepto. Cierto que los partidarios de la "vieja" Teorías Crítica no renuncian por completo a la posibilidad de una formación subjetiva autónoma. Dicho de otro modo, a la formación de un sujeto capaz de realizar el concepto pese al dominio que se ejerce sobre él. No obstante, los criterios y las posibilidades de su autonomía se colocan tan alto que finalmente esta idea sólo puede tomar forma en un Yo trascendental, y difícilmente en personas concretas. La posibilidad de vincularse a los planes de acción de los actores colectivos reales desaparece así entre el idealismo utópico de la teoría y el negativismo radical de sus descripciones empíricas. Cuestionar esto entre los partidarios de la Dialéctica del iluminismo es confrontarse inmediatamente con la insistencia de la teoría de la dominación. Reproche que no viene al caso.

Digamos que los "revisionistas" de la Teoría Crítica de la sociedad tienen tan sólo otro concepto de dominio. Para ellos la crítica de la sociedad es siempre una intervención comunicativa o un "performativer Akt"; es decir, que el comunicar se produce transformándose siempre a través de la reflexión de lo que se critica. Precisamente, localiza el dominio en la dimensión simbólica en la que los individuos y los grupos se hacen una figura de su voluntad y de sus circunstancias. El "dominio" no se sustrae así del ámbito de experiencia de las personas concretas ni por detrás de un destino que las mitiga. Por el contrario, de manera semejante a como en la historia de la formación individual, el "dominio" neurótico se expresa en los pantanos y bloqueos de la auto-experiencia interna, exteriormente el dominio político moderno se expresa también en los bloqueos sutiles, institucionales y culturales, del proceso de reflexión público en el que la sociedad aparece como tema. 


\section{LA ESCUELA DE FRANKFURT Y HABERMAS}

En su variante radical, la Teoría Crítica "clásica" se ocupa también del tejido de una teoría del dominio histórico triunfante. En ese sentido, al sostener ahora un valor de cambio que carece de límites, es una esfera pública omnipotente, una naturaleza, que ha sido destruida, una subjetividad funcional uniforme; la Teoría Crítica se convierte o aparece más bien como una filosofía de la historia. Su lectura de la vida social no indica una simple suma de acontecimientos contingentes sino un proceso dominado por una teleología negativa, es decir, por una continuidad de catástrofes. Los sucesos real-históricos adquieren significación apenas como momentos determinados del ámbito de fuerza de una ruina social que va prefigurándose y a partir de la cual, el acontecer no puede tener más realidad; ya ha acontecido. El presente es catástrofe: representación o recreaciones múltiples de un dominio expansivo e irracional sobre la naturaleza que conduce al caos. Incidentes claves fundamentales de este proceso son el propio establecimiento de la sociedad industrial, la polarización de los estereotipos sexuales ya en la sociedad burguesa temprana, o la actual evolución destructiva del sistema técnico-industrial. Para la Teoría Crítica clásica su propio contexto de surgimiento histórico, el nacional-socialismo, es un acontecimiento clave, relevante en su interpretación histórico-filosófica.

De manera semejante a como para Marx el capitalismo actúa como la pista que lo conduce al análisis de formaciones pre-capitalistas, para Adorno el carácter del dominio de la razón (Vernunft) sólo se hace accesible a partir del cenit histórico-mundial del fascismo, catástrofe contemporánea que esclarece las estructuras de toda evolución histórica posterior.

Las versiones de esta filosofía negativa de la historia apoyan, en este sentido y de forma contrafáctica un status quo utópico al que, sin embargo, se sabe que se la puesto fin por medio de la violencia: a la economía de subsistencia libre de dominio, a la natura naturans del matriarcado, a las relaciones simbólicas con la naturaleza, o a la esfera pública de la polis. Hechos que no son ya sino imágenes que han sido afectadas y que refieren un "algo" que se ha perdido de manera insalvable. La modernidad no tendrá más como recurso un potencial utópico positivo de salvación. 
Helmut Dubiel

Parece ahora difícil plantear una argumentación contraria al negativismo filosófico-histórico de la Teoría Crítica a partir de una situación histórica distinta. Incluso cuando en ciertas ocasiones las enseñanzas habermasianas sobre la evolución sean mal interpretadas por su críticos en este sentido. El negativismo de la Teoría Crítica sólo puede ser contrarrestado a través de una comprensión contemporánea de la realidad que hasta ahora no logra conformarse en una perspectiva teórica propia.

Mientras tanto, gran parte de la opinión pública política y científico social de los años 80 -por completo distinta a las de generaciones de izquierda de los 50 y 60 -se mantiene en la ilusión de un desarrollo social al cual, sin embargo, antes contradice que apoya, al reconocer también la prevalencia de un dominio totalitario (en su multiplicidad de formas aparentes). Al respecto, desordenadamente, pueden mencionarse: los límites hiper-molestos de la división taylorista del trabajo, la moralización pública del desarrollo técnico, la agudización dramática de la cuestión femenina, la creciente diversidad de formas y estilos de vida desarrollados de manera auto-consciente, la orientación coyuntural de los valores y una cultura hedonista del tiempo libre.

Todos estos fenómenos son altamente polémicos y extremadamente heterogéneos para una valoración empírica particular. Su importancia se revela y se expresa, sin embargo, porque se oponen a la superficial puntualización negativista del proceso histórico. Ninguno de estos fenómenos tomado en sí mismo, pero tampoco la suma de ellos, sustenta el supuesto optimista de un progreso evolutivo, a la manera como fue planteado por el pensamiento positivo del siglo XIX y principios del XX. Pero sí remplantean la cuestión de que el proceso civilizatorio ya no puede ser estudiado seriamente como totalidad.

Ahora bien, iqué significa en una dialéctica infructuosa el análisis de una teoría unilateral y caduca por un lado, y por el otro, el de una teoría evoluciónista? ¿Pueden imaginarse aún diagnósticos teóricos capaces de mostrar, sin detrimento de sus paradigmas explicativos, la multiplicidad de claroscuros del desarrollo antagónico de las sociedades modernas? 60 por el contrario, como ya Adorno parecía sugerir, esos 


\section{LA ESCUELA DE FRANKFURT Y HABERMAS}

"descubrimientos" de la teoría no son sino síntomas de un estado de transición, respecto al cual una teoría cerrada ya no es competente?

$\mathrm{Al}$ margen del ideal metodológico de aprehender lo real en una "descripción impermeable" (dichten Beschreibung), determinada y abierta por principios teóricos, está la cuestión meta-histórica de si en verdad tiene sentido plantear la alternativa ruina o progreso. Walter Benjamin describe un cuadro de la historia alejado de la esperanza y de la utopía de la felicidad -pero también de la imagen de una catástrofe prescrita- en la metáfora del ángel que rápidamente desaparece cuando concluye su impronta profética.

Advierte así sobre la posibilidad de la catástrofe siempre presente en el status quo, pero también que el "equilibrio de lo soportable" provisionalmente alcanzado ("Balance der Erträglichen", Jürgen Habermas) es un esfuerzo permanente de actores sociales que si bien confían en el progreso no saben por lo demás cómo garantizarlo. 